Moni toring and eval uat i on of si mul at ed under gr ound coal gasi fication in an ex-si tu experimental artificial coal seamsystem

\begin{tabular}{|l|l|}
\hline 著者 & $\begin{array}{l}\text { SU Fa- qi ang, HAMANAKA Aki hi ro, I TAKURA } \\
\text { Ken- } \mathrm{i} \text { chi, ZHANG Wenyan, DEGUCH Got a, SATOH } \\
\text { Kohki, TAKAHASH Kazuhi ro, KODAMA Jun- i chi }\end{array}$ \\
\hline $\begin{array}{l}\text { j our nal or } \\
\text { publ i cat i on t i tl e }\end{array}$ & Appl i ed Ener gy \\
\hline vol une & 223 \\
\hline page r ange & $82-92$ \\
\hline year & 2018 08-01 \\
\hline URL & ht t p: //hdl . handl e. net /10258/00009660 \\
\hline
\end{tabular}




\title{
Monitoring and Evaluation of Simulated Underground Coal Gasification in an Ex-situ Experimental Artificial Coal Seam System
}

\section{Fa-qiang Su ${ }^{a} *$, Akihiro Hamanaka ${ }^{\text {b }}$, Ken-ichi Itakura ${ }^{c}$, Wenyan Zhang ${ }^{d}$, Gota Deguchi ${ }^{\text {e }}$, Kohki Sato $^{c}$, Kazuhiro Takahashi ${ }^{c}$ and Jun-ichi Kodama ${ }^{f}$}

a School of Energy Science and Engineering, Henan Polytechnic University, 2001 Century Avenue, Jiaozuo, Henan, 454-003, China;

E-mail: sfqmuroran@gmail.com

b Department of Earth Resources Engineering, Kyushu University, Fukuoka, Japan;

E-mails: hamanaka@mine.kyushu-u.ac.jp

c Graduate School of Engineering, Muroran Institute of Technology, 27-1 Mizumoto, Muroran 0508585, Japan;

E-mail: itakura@mmm.muroran-it.ac.jp; ksatoh@mmm.muroran-it.ac.jp;

ktakahashi@mmm.muroran-it.ac.jp

d School of Materials Science and Engineering, Henan Polytechnic University, 2001 Century

Avenue, Jiaozuo, Henan, 454-003, China;

E-mail: zhangwy@hpu.edu.cn

e Underground Resources Innovation Network, NPO, Higashi-ku, Sapporo 007-0847, Japan;

E-mail: gota@mue.biglobe.ne.jp

f Graduate School of Engineering, Hokkaido University, Kita 13, Nishi 8, Kita-ku, Sapporo, 0608628, Japan;

E-mail: kodama@eng.hokudai.ac.jp

* Author to whom correspondence should be addressed; E-mail: sfqmuroran @ gmail.com;

\begin{abstract}
:
In this study, to better simulate underground coal gasification (UCG), an artificial coal seam was constructed to use as a simulated underground gasifier, which comprised coal blocks excavated from the coal seam. This study reports the process and results of three independently designed experiments using coaxial-hole and linking-hole UCG models: a) a coaxial model using a coaxial pipeline as a gasification channel, b) a coaxial model using the coaxial pipeline combined with a bottom cross-hole, and c) a linking-hole model using a horizontal V-shaped cross-hole. In the present work, the fracturing activities and cavity growth inside the reactor were monitored with acoustic emission (AE) technologies. During the process, the temperature profiles, gas production rate, and gas content were measured successively. The results show that AE activities monitored during UCG process are significantly affected by operational variables such as feed gas rate, feed gas content, and linking-hole types. Moreover, the amount of coal consumed during UCG process were estimated using both of the stoichiometric approach and balance computation of carbon (C) based on the product gas contents. A maximum error of less than $10 \%$ was observed in these methods, in which the gas leakage was also considered. This demonstrates that the estimated results using the proposed stoichiometric approach could be useful for evaluating
\end{abstract}


energy recovery during UCG.

Keywords: Underground coal gasification (UCG); Acoustic emission; UCG model; Gasified coal; Gasification rate

\section{Introduction}

Coal is primarily used as a solid fuel to produce heat and electric power through its combustion, and it is widely expected to be the primary energy source for this century. At present, less than $20 \%$ of the world's coal is too low in quality and too deep underground to be mined economically [1]. Improving the production and usage of existing coal resources is an important issue, but the environmental problems must be confronted.

Underground coal gasification (UCG) is a gasification process applied to unmined coal seams or abandoned coal from traditional mining methods; UCG uses an injection well (to supply the reactant gas such as air, oxygen, or steam) and a production well drilled from surface, which involves igniting coal underground and then collecting and using the synthesis gas that results from its gasification [2]. Applying the developed UCG technology to gasify deep and low-quality coal seams could greatly increase the amount of exploitable coal reserves. The coal could be converted to combustible gas for a variety of uses including producing electricity, serving as chemical feedstock, or serving as liquid fuel. Moreover, the emissions of sulfur, nitrous oxides, and mercury could also be reduced if a proper purification system is equipped during UCG. UCG has potential reduction of greenhouse gas [3] and the potential for carbon capture and storage in the underground gasified cavity [4-6].

As a clean coal technology, UCG has been discussed and experimented with for over 100 years [2]. This process has been employed at many pilot sites, including the former USSR, Europe, Australia, and India. Some of the pilot sites have produced commercial quantities of gas for power generation or chemical processes [2, 7-16]. In the 1960s, many pilot projects were abandoned due to the falling price of oil and natural gas. The Lawrence Livermore Laboratory in the USA has conducted over 30 pilot UCG projects, including the most recent two large-scale pilot projects in Washington and Wyoming $[2,17-19]$.

In recent years, much theoretical and experimental research has been performed to investigate the effect of various operational parameters of gasification [20-22] during the UCG process. Stańczyk reported the optimum air/oxygen ratio supplied in lignite gasification and hard coal gasification were respectively 2:4 and 3:2 [23]. Liu has performed the experiment to prove the hydrogen could release from coal seam at temperature between $350{ }^{\circ} \mathrm{C}$ and $825^{\circ} \mathrm{C}$ under special experimental conditions [24]. Laciak examined the effect of the gasification agent on the quality of product gas and presented that the reaction parameters of temperature, reactor pressure and composition of gasification agents should be correctly controlled for an effective UCG [25]. Perkins created a one-dimensional model to investigate the effects of operating conditions and coal properties on cavity growth [26]. The technoeconomic viability of hydrogen from UCG was examined in Western Canada [27]. Ali used a validated mathematical model to predict the product gas composition and temperature profile of UCG [28].

Gasification reaction in UCG process is promoted by enlargement of the oxidation surface around the gasification channel with crack initiation and development inside the coal seam. The most 
important chemical reactions taking place in gasification zone were reported in the work [29], which presented the impact analysis of oxidant on the product gas composition and calorific value in a laboratory gasifier. Fracturing activities inside the coal seam are accelerated with an increase of thermal stress caused by exothermic reactions and heat transfer, as a result, gasification reaction and cavity growth is promoted. Cavity growth influences gasification efficiency because it is directly proportional to the coal consumption. Although lots of field UCG trials have been performed, it has been possible to collect only a limited data on cavity growth in a target coal seam as the high cost and difficult in controlling the operating parameters. Currently, several researches were carried out to evaluate the cavity growth and the velocity of gasification flame based on mathematical model [3032]. These research are effective to estimate the volume and progress of cavity growth and create the design of UCG operation, however it is also needed to evaluate the cavity in real time during UCG operation because it is sometimes difficult to predict the cavity in coal seam precisely due to its heterogeneous characteristics. Daggupati [33] investigated the effect of various design and operational variables on the evolution of the gasification cavity. And their previous works [34] had given the various features of the UCG cavity shape and cavity growth rate through laboratory model experiments. Lawrence Livermore National Laboratory (LLNL) reported the cavity growth rate in the vertical direction predicted is about $1.6-5 \mathrm{~cm} / \mathrm{h}$ [35]. The similar values of cavity growth also be predicted in work [36] that developed a mathematical model. Available model experiment conducted at LLNL [37, 38] show the cavity growth under distinct operating parameters in a horizontal gasification channel of a coal block. Few researchers [39, 40] also attempted to perform the experiments to understand the growth of the sidewall in underground coal gasification.

However, UCG also involves several environmental risks: gas leakage, contamination of groundwater, and subsidence of overlying rock. These environmental risks are caused by the cavity growth associated with fracturing occurred during UCG process. Therefore, unless an evaluation method for monitoring fracturing activity and cavity growth is developed, it will be difficult for UCG to become an acceptable replacement for the traditional mining techniques.

This study presents a feasibility study of UCG by applying the Coaxial model and conventional Linking-hole model in an artificial coal seam. The Coaxial UCG is expected for use as a local energy source in small communities as the cost of constructing the drill holes and ground equipments are lower than those for traditional UCG with a linking hole. The acoustic emission (AE) technique was employed to monitor the fracturing and cavity growth that occurred during the experiments. The main objectives of this study are as follow: a) to determine the influence of linking-hole types on the gasification effect; b) to determine the effect of the feed gas rate and reactant gas on the product gas compositions; c) to determine the feasibility of acoustic emission monitored during the gasification process to evaluate fracturing activities and cavity growth; and d) to estimate the coal consumption using a proposed stoichiometric approach.

\section{Materials and Methods}

\subsection{Experimental apparatus}

Evaluation of the underground combustion area and the fracturing activity inside a coal seam are crucial for the development of UCG system with high efficiency and safety. With the development of 
the UCG technology, many design approaches have arisen for underground reactor structures. Herein, the UCG system was prepared within an artificial coal seam for three independent tests: a coaxial model, a coaxial model with a bottom cross-hole, and a linking-hole model using an approximately horizontal V-shaped cross-hole as presented in Fig. 1. This experimental unit was equipped with a reactant gas supply system, a simple purification system (which cooled hot gas to filter the tar and water), and a gas chromatograph for analyzing the product gas. The artificial coal seam was designed to have a rectangular shape with dimensions of 2.74 (length) $\times 0.60$ (width) $\times 0.55 \mathrm{~m}$ (height). The artificial coal seam was covered by the steel plates and the concrete structure to prevent the heat loss and gas leakage. The coaxial-holes in Tests 1, 2 and linking-hole in Test 3 were drilled in advance as gasification channels with 35-mm-diameter, as shown in Fig. 2. The coal block samples which were more than $0.5 \mathrm{~m}$ diameter were excavated from an open-cut coal mine (Sanbi Ming Co., Ltd of Japan), and joined together with concrete cemented in the gaps and surrounding parts to create a continuous coal seam. Table 1 shows the results of ultimate and proximate analyzes of coal sampled from coal seam.

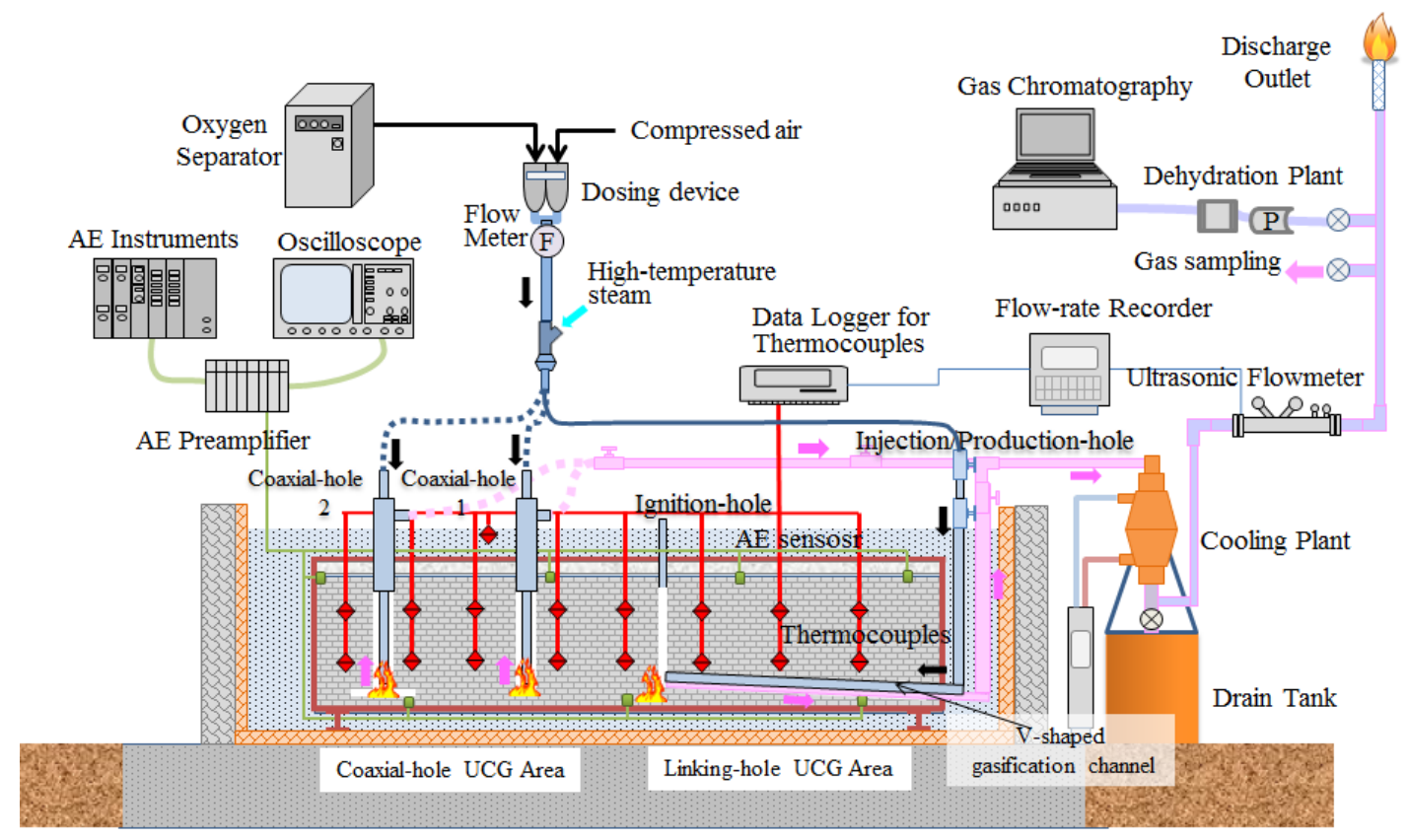

Fig. 1. Schematic of the simulated UCG System with two coaxial-hole models and one linking-hole model.
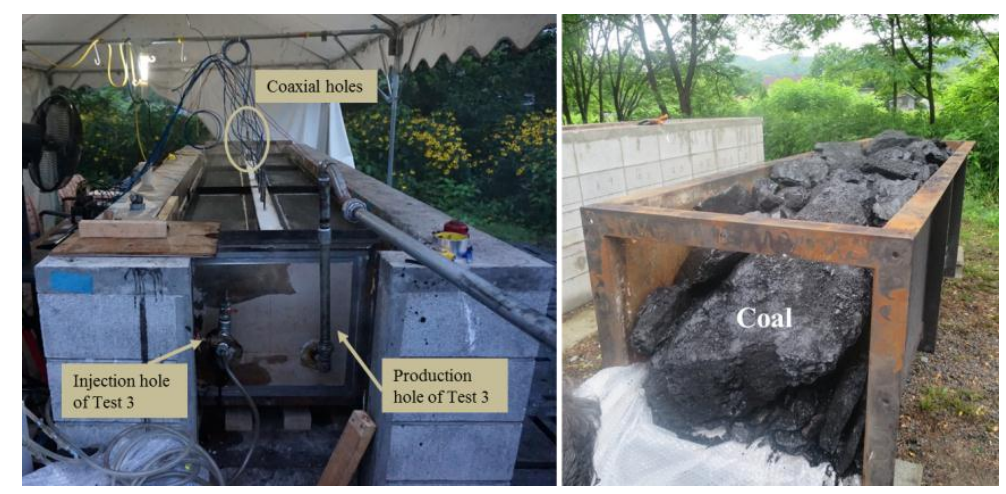

Fig. 2. Construction of UCG model. 
Table. 1. Proximate and ultimate analyzes of coal samples.

\begin{tabular}{|c|c|c|c|}
\hline No. & Parameter & Sanbi coal & \\
\hline \multicolumn{4}{|c|}{ Proximate analysis /[wt $\%]$} \\
\hline 1 & Moisture & 2.10 & JIS M8814 \\
\hline 2 & Ash content & 4.30 & JIS M8814 \\
\hline 3 & Volatile matter & 43.10 & JIS M8814 \\
\hline 4 & Fixed carbon & 50.50 & JIS M8814 \\
\hline 5 & Total sulfur & 0.07 & JIS M8814 \\
\hline \multicolumn{4}{|c|}{ Ultimate analysis /[wt $\%]$} \\
\hline 6 & Carbon & 78.40 & JIS M8814 \\
\hline 7 & Hydrogen & 5.74 & JIS M8814 \\
\hline 8 & Nitrogen & 1.44 & JIS M8814 \\
\hline 9 & Oxygen & 9.94 & JIS M8814 \\
\hline 10 & Ash (Dry) & 4.4 & JIS M8814 \\
\hline 11 & S & 0.07 & JIS M8814 \\
\hline 12 & Gross calorific value $/[\mathrm{MJ} / \mathrm{kg}]$ & 32.12 & JIS M8814 \\
\hline
\end{tabular}

\subsection{Experimental procedure}

Descriptions of the three independent experiments mentioned above are presented in Table 2. These three experiments of Tests 1, 2 and 3, were carried out in the artificial coal seam. Oxygen-enriched air is injected into the combustion reactor to sustain the gasification process. The feed gas flow rates in distinct time periods during each gasification experiment are shown in Fig. 3. Carbon dioxide and nitrogen were applied to extinguish the combustion in the last stage of the gasification process. In this ex situ UCG model, the actual underground conditions can be simulated. The locations of the AE sensors and thermocouples are depicted in Fig. 4.
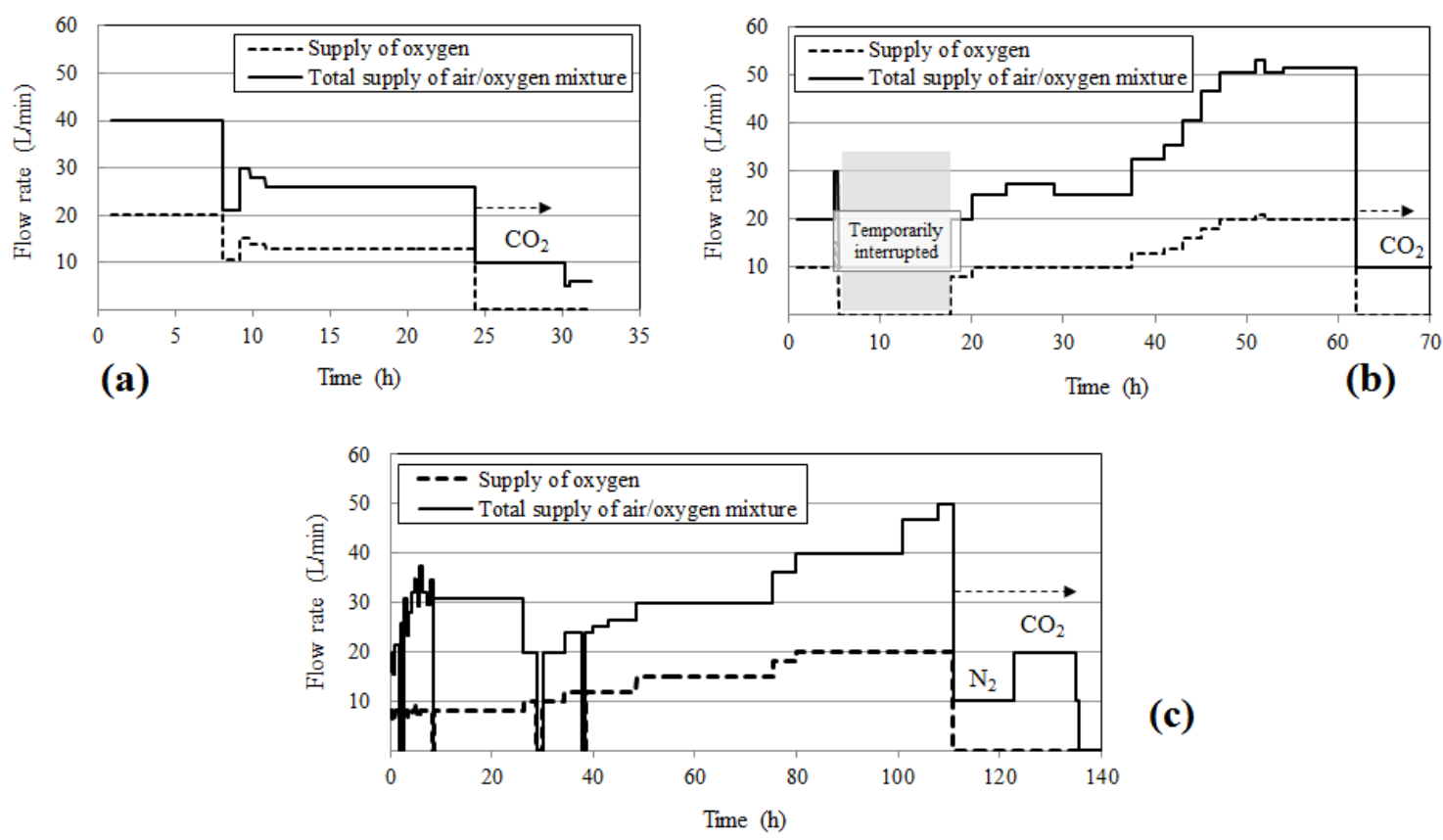

(c)

Fig. 3. Feeding gas procedure: (a) Test 1, (b) Test 2, (c) Test 3.

Table. 2. Operating parameters. 


\begin{tabular}{cccc}
\hline No. & Test 1 & Test 2 & Test 3 \\
\hline Models & Coaxial-hole model & $\begin{array}{c}\text { Coaxial-hole model } \\
\text { with a bottom cross-hole }\end{array}$ & $\begin{array}{c}\text { Linking-hole model with a } \\
\text { horizontal V-shaped linking-hole }\end{array}$ \\
Ignition location & Bottom of coaxial hole & Bottom of coaxial hole & Bottom of ignition hole \\
Operation time $/[\mathrm{h}]$ & 31 & 63 & 110 \\
Reactant gas & Oxygen-enriched air & Oxygen-enriched air & Oxygen-enriched air \\
Fire-extinguishing gas & about $60 \%$ & about 50\% & about 60\% \\
\hline
\end{tabular}

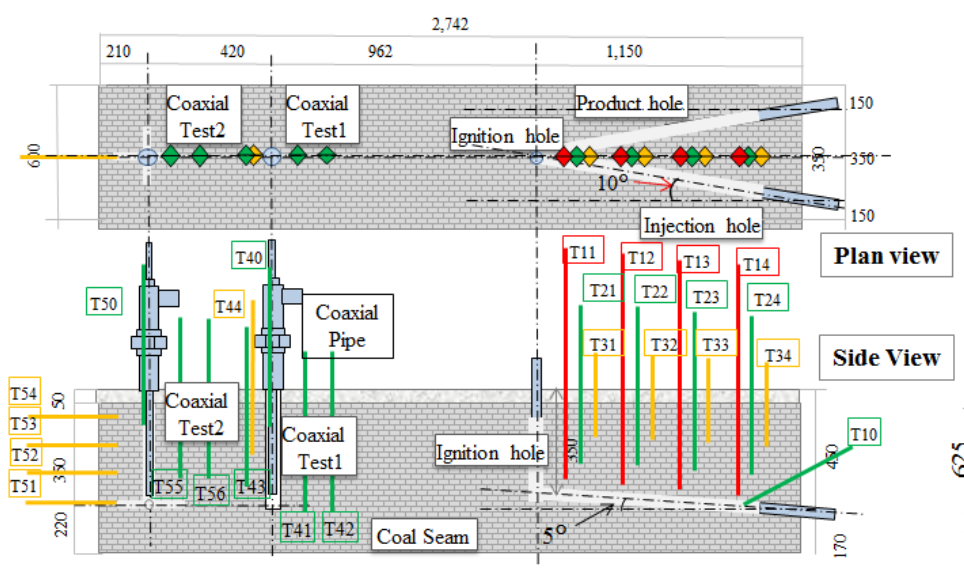

(a)
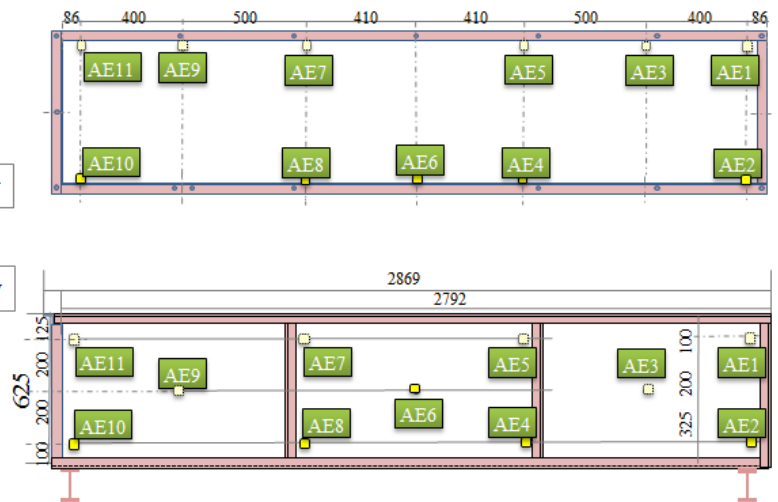

(b)

Fig. 4. Arrangement of the sensors in the ex-situ reactor: (a) Thermocouples, (b) AE sensors.

This study presents the results of analyzing the AE parameters from AE signals that comprise the count rate and events. The AE events and count rates obtained from the sensors were recorded using a data logger (GL900; Graphtec Corp., Yokohama, Japan), which depicts the number of cracks initiated inside the coal and reflects the strength of an event. All AE waveforms from the sensors were first recorded using a multi-recorder (GR-7000; Keyence Co., Osaka, Japan) with a sampling time of $10 \mu$ s. They were then processed using a computer. These AEs occurred together with crack generation and development in the coal, which were caused by the energy released under thermal stress. The AE technology has a great potential for use in process monitoring. In particular, the location capability of the $\mathrm{AE}$ technique is often considered its most powerful attribute. It reveals damage positions during coal gasification that cannot be readily observed at the surface. The purpose of source location is to determine the true coordinates of the source and the onset time for an $\mathrm{AE}$ event, based on the sensor coordinates, times of arrival, and velocities of P-waves. The least-squares arrival-time-difference method (reported by [41, 42]) was employed for determining the AE clustered positions during the gasification operations in these experiments.

\section{Results and Discussion}

In this section, we first present the temperature profiles and observations of fracturing, i.e., a flag parameter of crack initiation (an $\mathrm{AE}$ event), to preliminarily reveal the relationship between the temperature change and the AE activity. Furthermore, the AE source was located using the parameters obtained from recorded signals during the gasification process to discuss the correlation between the 
clustered AE region and the temperature of coal seam. Next, the gas quality, gasification efficiency, and coal consumed in the tests were estimated to discuss the energy recovery using the stoichiometric approach proposed in our previous work [43]. For comparison, the method of balance computation (reported by Wiatowski et al. [44]) was also applied to investigate the coal consumption during the gasification process.

\subsection{Fracturing activity and cavity growth}

Fig. 5 (a) shows temperature profiles recorded over the gasification process of Test 1 at six positions (see Fig. 4): four of them around coaxial hole 1 at different depths, and two at horizontal distances of $22 \mathrm{~cm}$ and $32 \mathrm{~cm}$ from the ignition point. The temperatures of thermocouples T43 and T44 located in the upper part along the coaxial hole successively increased to over $800{ }^{\circ} \mathrm{C}$ and $1,000{ }^{\circ} \mathrm{C}$, respectively. Subsequently, the peak value of the temperature in the gasifier was approximately 1,200 ${ }^{\circ} \mathrm{C}$, as recorded by thermocouple $\mathrm{T} 41$, which was located nearest the bottom of the hole. After more than $10 \mathrm{~h}$ of operation, temperatures of thermocouples T55 and T56, which were situated at a distance, also started to rise and respectively reach over $600{ }^{\circ} \mathrm{C}$ and $400{ }^{\circ} \mathrm{C}$. The results show that the gasification zone moved in a downward direction along the coaxial hole and continued to expand around it. The gasification was terminated by injecting carbon dioxide after about $24 \mathrm{~h}$ of continuous experiments. It can be seen that the local temperatures of the reactor decreased rapidly.
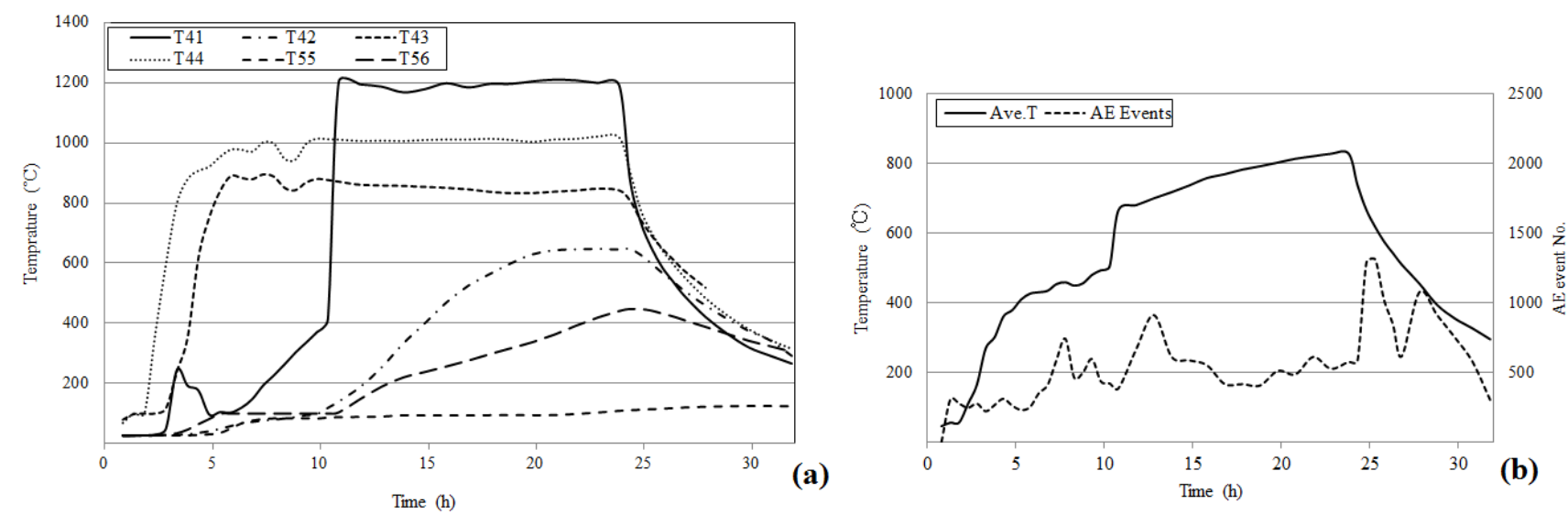

Fig. 5. (a) Temperature profiles; (b) average temperature vs AE event during gasification process of Test 1 .

The temperature profiles and AE activity monitored in Test 2 are presented in Fig. 6. The temperatures of T55 and T56 first increased in the initial stage after the coal ignited. The thermocouples T51, T52, T53, and T54 increased thereafter, and maximum temperature peaks of 1,200 ${ }^{\circ} \mathrm{C}$ were recorded in the reactor. This fact means that the combustion front expanded from the bottom of coaxial hole 2 to an upward direction. The difference in the expanding directions and temperature fields in Tests 1 and 2 could be caused by the preset cross-hole prepared in the bottom of coaxial hole 2 in Test 2 and the distinct supply rates of the reactant gas. 

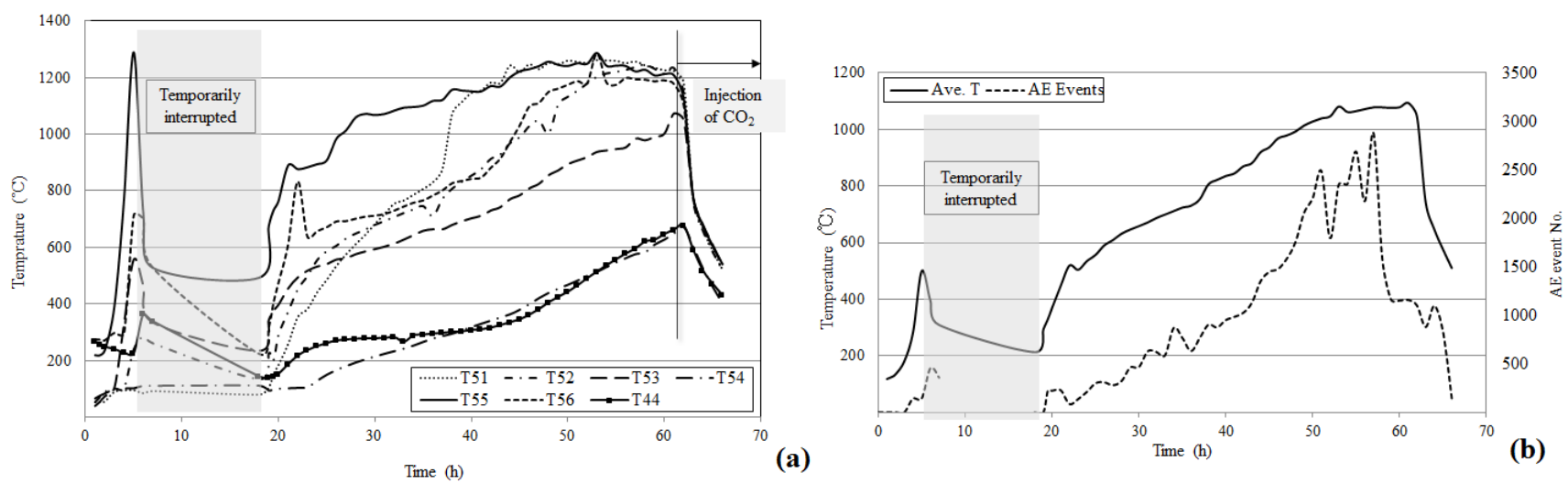

Fig. 6. (a) Temperature profiles; (b) average temperature vs AE event during gasification process of Test 2.

For the linking-hole model Test 3, the injection and production wells were drilled in a plane and inclined at $5^{\circ}$. The measured temperatures inside the coal seam at different slope-planes above the gasification channel of Test 3 are shown in Fig. 7. The temperatures recorded by T11 and T21 rise rapidly in the initial stage after igniting the coal. These temperatures, however, decreased rapidly after about $5 \mathrm{~h}$ of operation. T14 and T13 around the inlet of oxidant then showed a significant increase in temperature. This fact indicates that the gasification zone expanded at the beginning and not from the ignition area but from the oxidant inlet. Yong et al. [32] pointed out the difficulty of laboratory experiments on reverse combustion because of the coal characteristics and dimensions of the experiments. Test 3, therefore, switched from reverse to forward combustion because the gasification channel length was insufficient for the velocity moving a fire. Finally, the combustion zone expanded over a wide range because most of the thermocouples showed readings of more than $900{ }^{\circ} \mathrm{C}$.
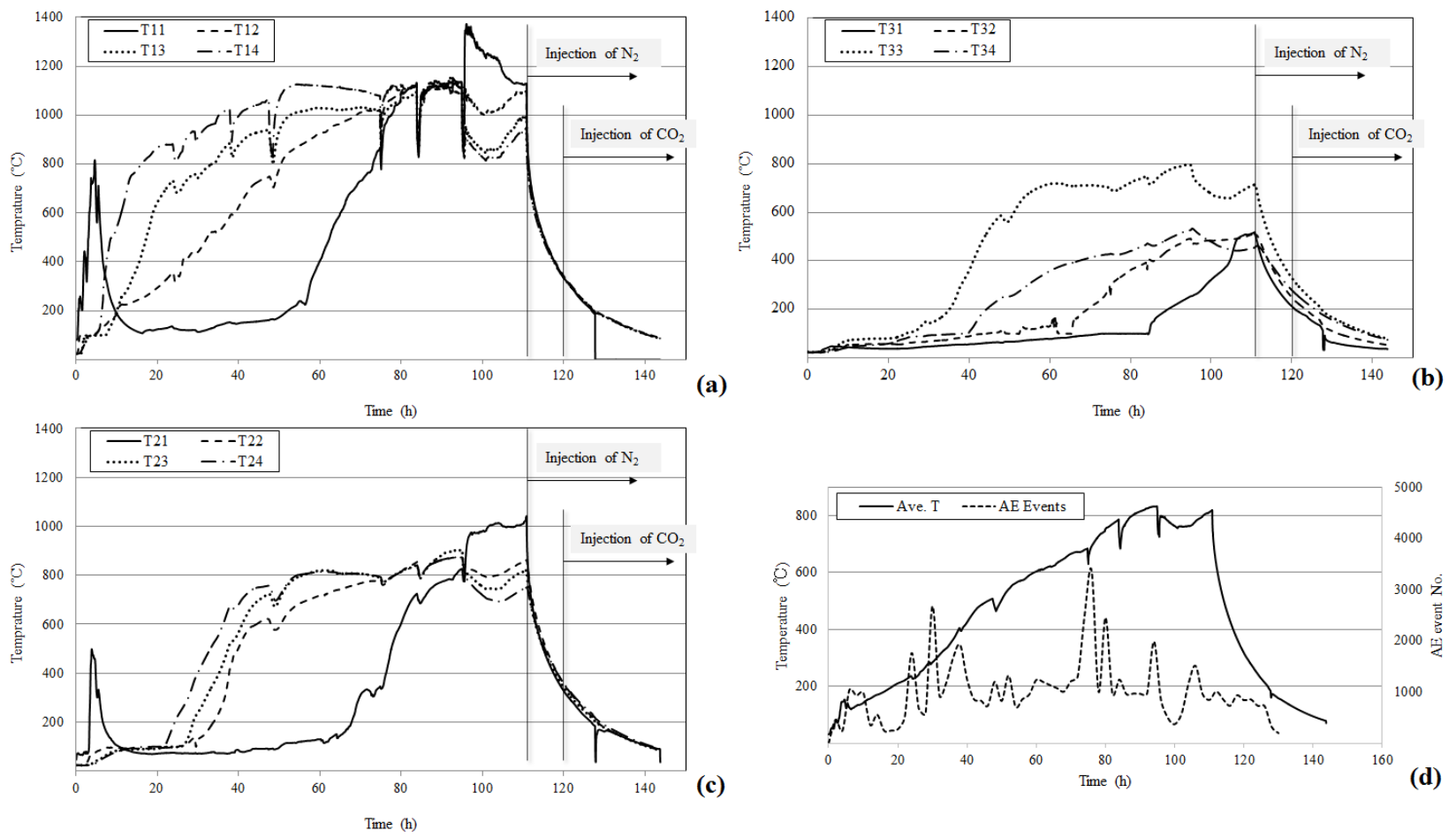

Fig. 7. Measured temperatures of coal near the gasification channel $(10 \mathrm{~cm})$ (a), distance from gasification channel at $20 \mathrm{~cm}$ (b) and $30 \mathrm{~cm}$ (c); and average temperature of reactor vs AE event (d) during gasification process of Test 3 . 
We found that the AE activities were closely related to changes in local temperature inside the gasification zone [42]. To better elucidate the AE generation during the gasification process, we tried to obtain the correlation between the number of $\mathrm{AE}$ occurrences and the rate of temperature change inside the gasifier. Fig. 8 shows the occurrence of $\mathrm{AE}$ events under the different change rate of temperature, wherein the values of temperature represent the temperature change of the reactor per hour during the gasification process. Similarly, the relevant monitoring data in the coal ignition phase is ignored because the ignition approach and intensity could affect the results. It was found that the number of $\mathrm{AE}$ generally rises along with the increment of the temperature change rate. It can be seen that the AE activity is relatively high during the temperature variation between $400{ }^{\circ} \mathrm{C}$ and $900{ }^{\circ} \mathrm{C}$. Furthermore, the rate of $\mathrm{AE}$ increase gradually drops when the temperature rises to over $1,000{ }^{\circ} \mathrm{C}$. At this experimental stage, the temperature field of the reactor might have larger temperature bases while no drastic combustion occurred. Another possible cause could be the cumulative events that showed a decreasing tendency when a certain amount of microcracks were generated inside a fixed area of coal during the UCG process.

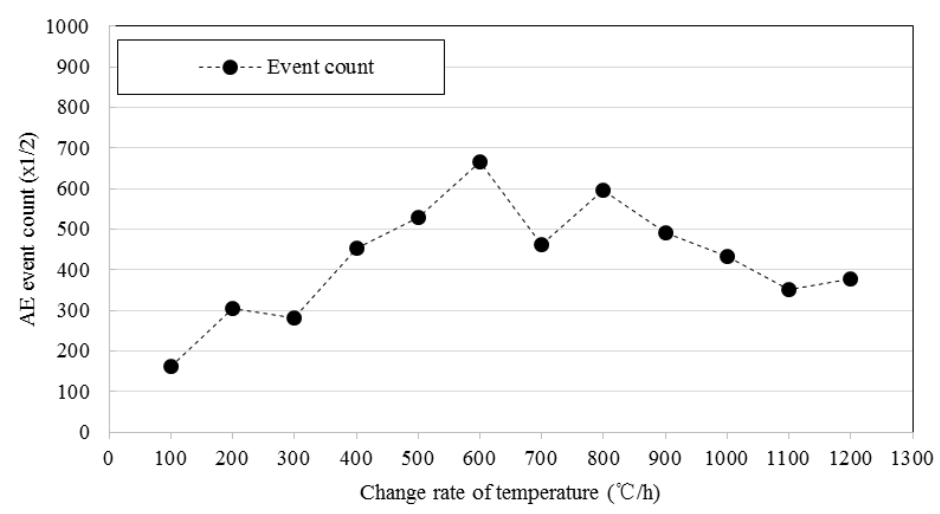

Fig. 8. AE event occurring vs change rate of temperature in reactor.

It is apparent that AE activity occurred while the local temperatures changed inside the coal. However, it should be noted that the use of AE events in combination with temperature profiles cannot indicate the damage extension and cavity growth in the UCG reactor. To further reveal the fracturing characteristics in the gasification zone at different operation stages, a real-time source locating method was used to locate the events that occurred during the gasification process. The processable AE event numbers are 2745 (Test 1), 4232 (Test 2), and 16195 (Test 3), respectively. The number of recorded waveforms in Tests 1 and 2, to which the position calculation is applicable, is limited due to high noise, excessive attenuation, or other unknown factors. 

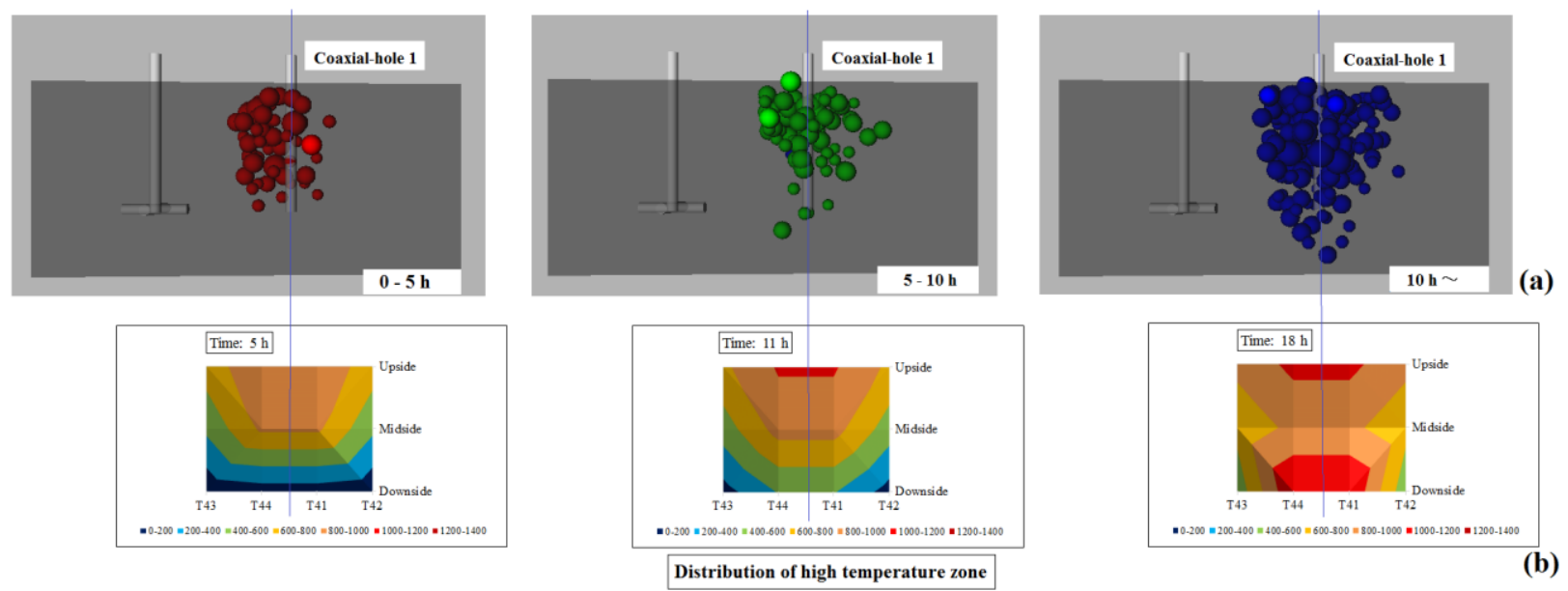

Fig. 9. Compared results between AE monitoring and temperature in Test 1: (a) AE source locations, (b) Temperature distribution.

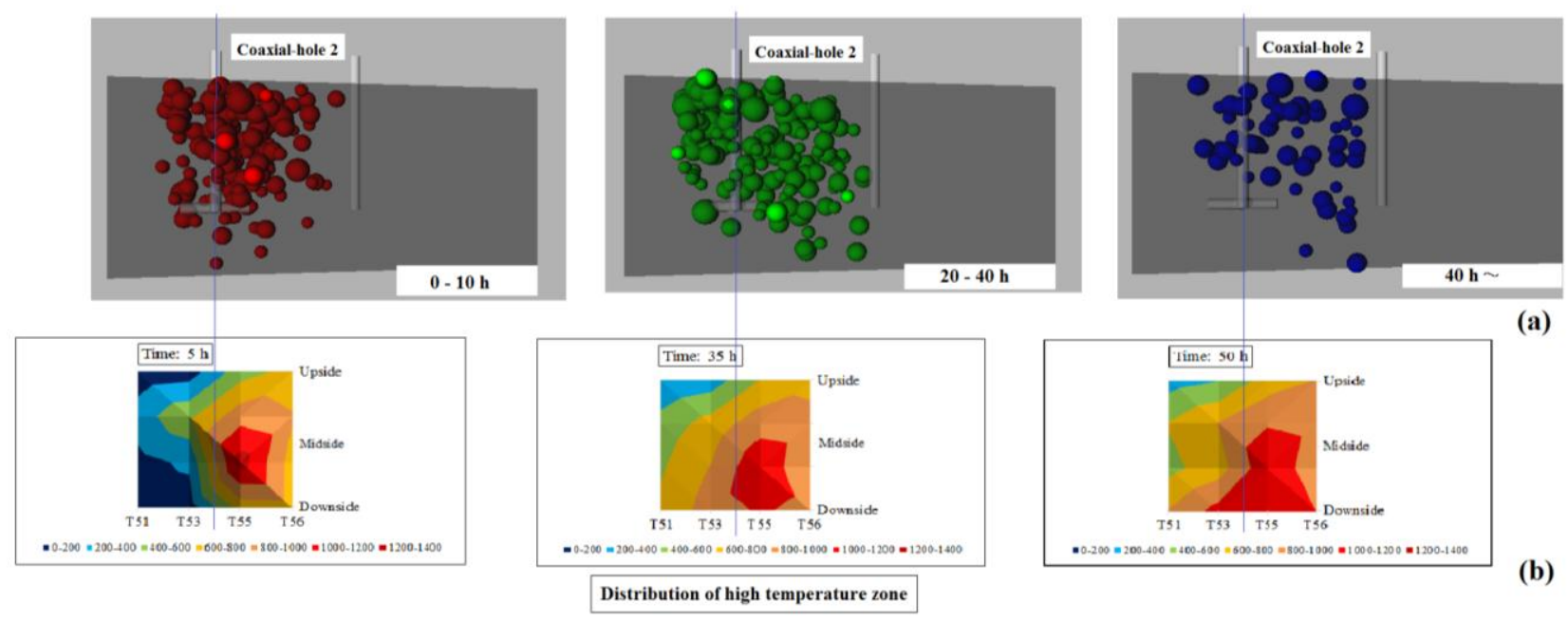

Fig. 10. Compared results between AE monitoring and temperature in Test 2: (a) AE source locations, (b) Temperature distribution.

The results of the spatial distribution of the AE sources and temperature in these three tests are shown in Figs. 9-11. The corresponding distributions of high-temperature fields along the longitudinal section were obtained using the measured temperature from thermocouples. The AE sources located in different experimental stages are distinguished using different colors of sphere. The size of the spheres represents the extent of damage, i.e., the relative energy emitted from a damage event. The extent and movement of the combustion and gasification volume inside the coal seam can be estimated from the AE source locations. In Test 1 , the AE sources were concentrated around the upper part of coaxial hole 1 between 0 and $10 \mathrm{~h}$. The AE source clouds then expanded and moved downward along the coaxial hole. The AE sources obtained from Test 2 show that the gasification region is expanded widely not only in the upper part but also in the lower part of coaxial hole 2 . The cavity propagated from the bottom of the coal seam to the upper side along the coaxial hole and continued to expand around it. These trends are comparable with the temperature increment. In Test 3 of the linking-hole model, numerous AE events occurred in the middle part of the injection well between 0 and $30 \mathrm{~h}$. Subsequently, the AE sources expanded widely and moved in the upward direction. These results 
mean that the gasification process was promoted around the inlet of the oxidant at the beginning of the experiment, and then the gasification zone expanded over a wide range. It is observed that the fracturing obtained from the AE source locations coincides with the results of the propagation of the combustion front and the gasification zone in the temperature profiles. Additionally, a mixture of white cement and gypsum was poured into the post-gasification cavity after the experiment to investigate the cross-section of the gasification zone. Fig. 12 shows a comparison of the actual cross-sectional photograph and the located AE sources in the corresponding vertical cross section. These results agree with those obtained from the temperature profiles and the AE source location. For Tests 1 and 2, a limited number of AE events were available in the dissected sections. Overall, the located AE source locations reflect the approximate extent of the gasification zone, and they appear as a red outline in the photograph of the gasification zone cross section in these experiments.

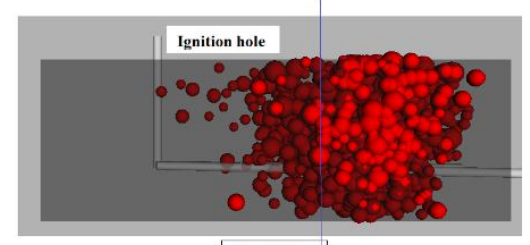

0 - 30 h
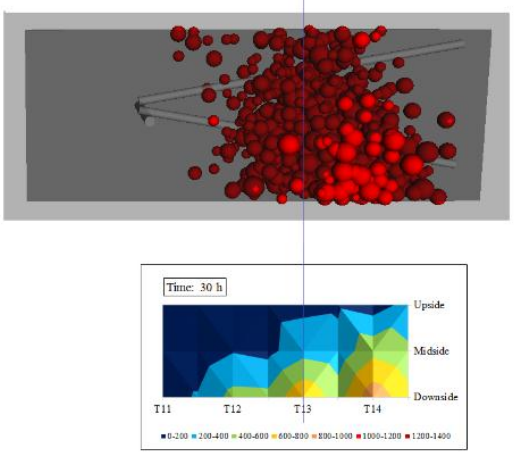
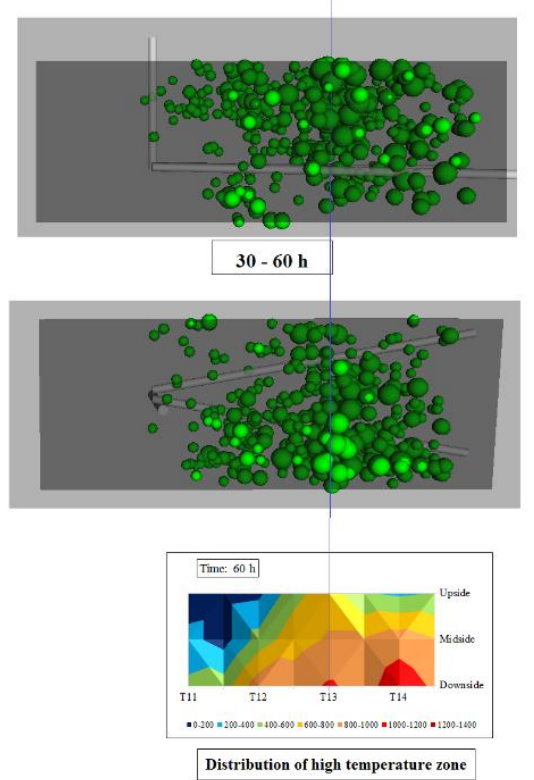
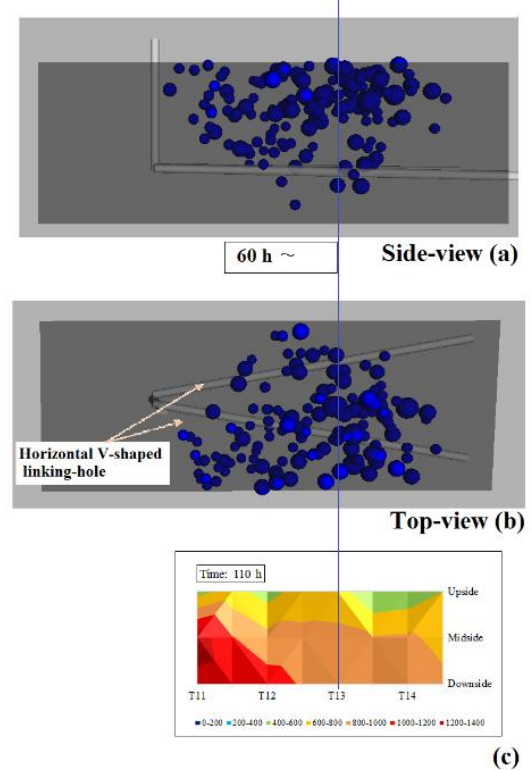

Fig. 11. Compared results between AE monitoring and temperature in Test 3: (a) AE source locations, (b) Temperature distribution. .
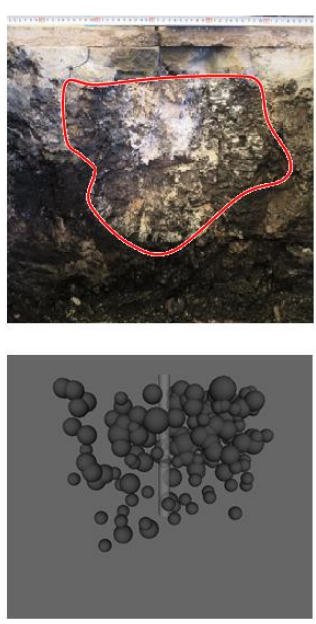

Test 1
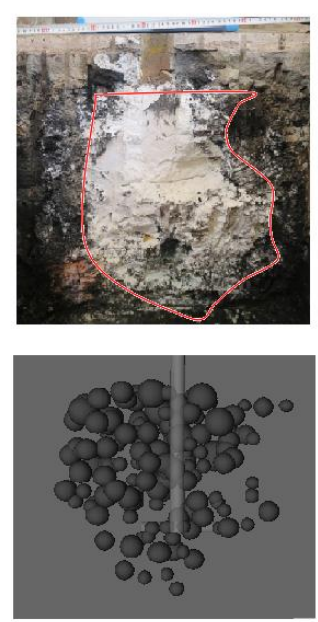

Test 2
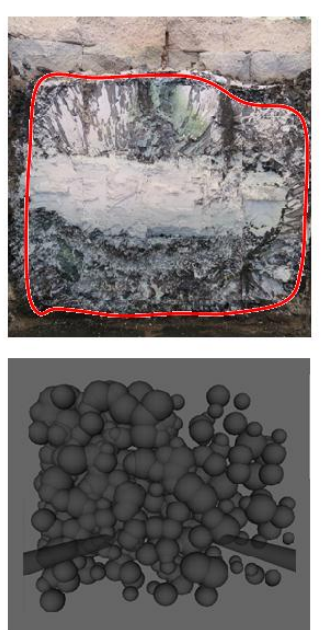

Test 3

Fig. 12. AE source locations and actual cross-sectional photograph in the same positions during three tests. 
The monitored AE events and source locations are two of the most important parameters of AE monitoring employed in the UCG process; one is important for excess fracturing warning and control in an underground reactor by adjusting the operational variables, and the other is for the prediction of the gasification zone such as its position, scope, and propagation, which could be used to visualize the underground gasifier and improve the safety performance and mitigate environmental risks. In the actual UCG process, the geophone could act as a kind of low frequency of micro-seismicity activity sensors, which could be used to monitor the fracturing activities occurring inside the underground gasifier. And the function of geophone is similar to that of AE accelerometer. That is, it is possible to obtain the parameters, such as, event, count rate, and relative energy parameters by processing the recorded voltage signal from the wave detector. AE monitoring is a useful technique to detect the fracturing during UCG process, but it is difficult to predict the amount of coal reacted directly. Other reliable methods to evaluate coal consumption during UCG are strongly needed to ensure the monitoring system. Therefore, we discuss the estimation of the amount of coal consumed during UCG process using the data of product gas volume and components.

\subsection{Evaluation of coal consumption}

In the UCG process, the complex phenomenon of combustion and the amount of gasified coal cannot be readily observed in situ. The consumption of coal causes an underground cavity creation and subsequent growth continuously during the gasification process. The amount of coal consumption is governed by the extent and rate of the reaction that takes place in the reactor, both of which have been regarded as important parameters of efficient gasification. It is apparent that actual coal gasification is difficult to simulate precisely by application of reliable scientific analysis of fundamental experiments. Coal gasification is extremely complicated from both experimental and theoretical points of view. Its chemical processes cannot be grasped comprehensively solely by the accumulation of kinetic data. However, as an important appraisal, a few data are available on the evaluation of the product gas energy from distinct underground gasification reactors. In this study, a useful method of balance computation [44] is applied to discuss the amount of coal gasified over the experiment. Additionally, the amount of coal consumption is compared with the results from a proposed stoichiometric method (reported in our previous work [43]) which can be calculated by the product gas composition and oxygen injection rate.

\subsubsection{Product gas compositions}

Fig. 13 presents the course of the measured syngas contents (combustible gas contents and $\mathrm{O}_{2}, \mathrm{~N}_{2}$, and $\mathrm{CO}_{2}$ ) throughout the whole experiment in Tests 1,2, and 3. A similar varying tendency of product gas concentrations was observed in Tests 1 and 2. A considerable concentration of CO (40\%-50\%) was reached after ignition in the early stages of the two tests. During the initial part of these two tests, the temperatures around the ignition area (T43, T44, and T55, T56) increased rapidly and reached relatively high values $\left(800-1000{ }^{\circ} \mathrm{C}\right)$. Later in the tests, the $\mathrm{CO}_{2}$ contents increased, whereas $\mathrm{CO}$ contents and the calorific values decreased gradually. After about $10 \mathrm{~h}$ of operation, the temperatures achieved a highest value in the Test 1 (T41 recorded $1200{ }^{\circ} \mathrm{C}$ ). At this time, the calorific value estimated from these gas contents also arrived at a second peak value $\left(8.4 \mathrm{MJ} / \mathrm{Nm}^{3}\right)$. In fact, $\mathrm{H}_{2}$ maintained a stable concentration (about 10\%) during each test. Also, $\mathrm{CH}_{4}$ was weakly detected 
throughout the experiments. At the end of Test 1, the $\mathrm{CO}$ content and the calorific value decreased to $10 \%$ and $1.5 \mathrm{MJ} / \mathrm{Nm}^{3}$, respectively, and the $\mathrm{CO}_{2}$ content was about $40 \%$. Corresponding to the same time period around Fig. 5, the temperatures also show a decreasing trend. Nevertheless, stable values were maintained in Test 2 because of its gradually increased injection flow (see Fig. 3); the CO content was $25 \%-30 \%$, the calorific value fluctuated near $5.0 \mathrm{MJ} / \mathrm{Nm}^{3}$, and the $\mathrm{CO}_{2}$ content was about $20 \%$. The each thermocouple gradually rose and respectively reached high levels. Temperature at T55 showed a higher growth rate, which located around the bottom of coaxial hole. After about $60 \mathrm{~h}$ of operation, the continuous increase of thermocouple T54 depicted that the reactor had expanded to the coal seam border inside model. The monitoring results obtained for Test 3 exhibit differences from those of Tests 1 and 2. The $\mathrm{CO}$ content remained at about $30 \%$ until about $70 \mathrm{~h}$ elapsed since the beginning of the test. The calorific value and $\mathrm{CH}_{4}$ content showed similar tendencies; they showed higher values between 10 and $25 \mathrm{~h}$, and decreased gradually after $60 \mathrm{~h}$ of operation. At about $95 \mathrm{~h}$, the calorific value of product gas showed a sudden marked increase. As process proceeded, maximum temperatures also were being recorded by thermocouples T11, T12, T13, and T14 in the cavity space. Actually, $\mathrm{H}_{2}$ maintained a stable concentration during the experiment. Additionally, the combustible contents and the calorific value increased after $95 \mathrm{~h}$ because the inlet of oxidants was changed from an injection to an ignition well to promote the gasification reaction on the production well side. These data ate are mainly attributable to the different thermal states of the gasifier achieved during the respective time periods. Changes in the local temperature of the reactor as the gasification process proceeded also affected the product gas concentrations.

According to the product gas results for each test given in Table 3, the average calorific values in the coaxial UCG system are similar: $5.11 \mathrm{MJ} / \mathrm{Nm}^{3}$ in Test 1 and $5.51 \mathrm{MJ} / \mathrm{Nm}^{3}$ in Test 2 . Test 3 of the linking-hole model yielded a relatively high value of $8.43 \mathrm{MJ} / \mathrm{Nm}^{3}$. As can be seen from Table 3 , the $\mathrm{CO}$ content significantly influences the calorific value of the product gas in these experiments. Results in Table 3 show that the average methane content ranged from about 1.3\%/0.7\% for gasification with Coaxial system to about $7.5 \%$ during gasification with an Linking-hole system. The broken coal was also employed for constructing the artificial coal seam in our previous ex-situ UCG experiments [45]. The average calorific values of product gas obtained in the Linking-hole model and Coaxial model were respectively $8.78 \mathrm{MJ} / \mathrm{Nm}^{3}$ and $4.37 \mathrm{MJ} / \mathrm{Nm}^{3}$, which is of the same order as results of this study conducted using the large size coal block. 

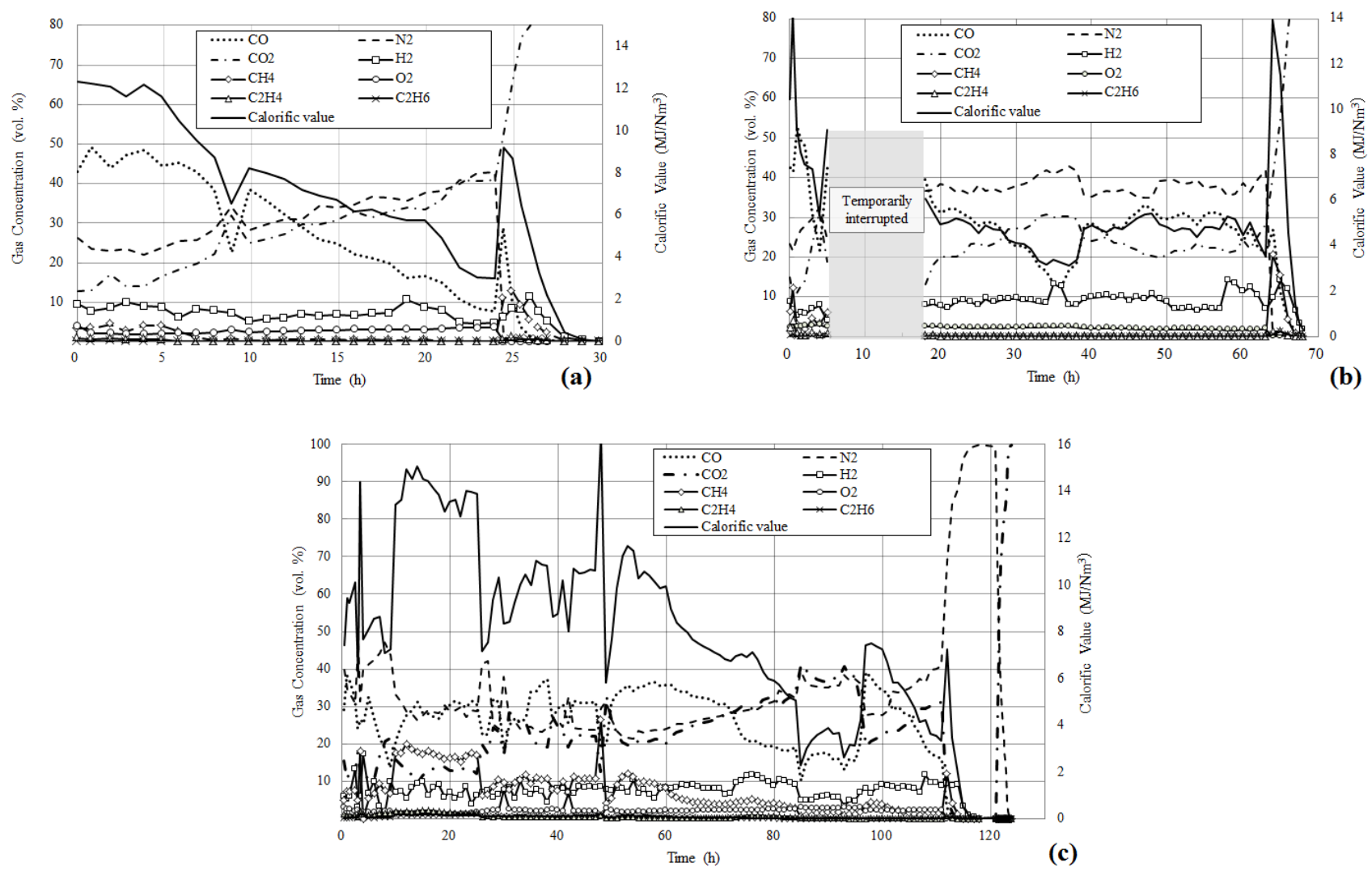

Fig. 13. Changes in product gas compositions and calorific values vs operation time in Test 1 (a), Test 2 (b), and Test 3 (c).

Table. 3. Average gas compositions of product gases.

\begin{tabular}{ccccccccc}
\hline $\begin{array}{c}\text { Average gas } \\
\text { composition }\end{array}$ & $\mathrm{O}_{2}$ & $\mathrm{~N}_{2}$ & $\mathrm{CO}_{2}$ & $\mathrm{CO}$ & $\mathrm{CH}_{4}$ & $\mathrm{H}_{2}$ & $\mathrm{C}_{2} \mathrm{H}_{6}$ & Average calorific value \\
\hline Coaxial model test 1 & 2.8 & $\%$ & $\%$ & $\%$ & $\%$ & $\%$ & $\%$ & $\mathrm{MJ} / \mathrm{m}^{3}$ \\
\hline $\begin{array}{c}\text { Coaxial model test 2 } \\
\text { Linking-hole model } \\
\text { test 3 }\end{array}$ & 2.2 & 36.2 & 22.8 & 29.1 & 0.7 & 8.7 & 0.2 & 5.11 \\
\hline
\end{tabular}

\subsubsection{Calculation of coal consumption}

In the present work, the effect of gas leakage also has to be regarded when predicting the energy generation of gaseous products because a great amount of gas leakage occurred during the experiment. The amount of gas leakage can be inferred from the amount of nitrogen, which is an inert gas not related to the chemical reactions that occur in the UCG process. The total gas leakage is calculated $34.4 \%$ for Test $1,22.01 \%$ for Test 2 , and $51.6 \%$ for Test 3 .

To better evaluate the coal consumption during the gasification process, a useful method of balance computation [44] is applied to discuss the amount of coal gasified over the experiment. The amount of gasified coal is calculable by the balance of carbon, as shown in Table 4. The amount of carbon content in a tar is not included in the balance sheet. The amounts of carbon in Tests 1, 2, and 3 are, respectively, $18.99 \mathrm{~kg}, 37.66 \mathrm{~kg}$, and $87.92 \mathrm{~kg}$, meaning that $24.23 \mathrm{~kg}, 48.04 \mathrm{~kg}$, and $121.60 \mathrm{~kg}$ of coal 
are expected to have been gasified. Considering that the gross calorific value of coal is $32.12 \mathrm{MJ} / \mathrm{kg}$, the gasification efficiency, i.e., the energy recovery rate from coal, could be obtained as presented in Table 5. The gasification rate of the unit coal in Tests 1 and 2, which simulate a coaxial-hole UCG system, were $49.12 \%$ and $43.01 \%$, respectively. By contrast, that in Test 3 of the linking-hole model was rather high at $71.81 \%$. Comparison of the results shows that the coaxial UCG system has a lower rate of energy recovery from coal than the linking-hole UCG system under the experimental conditions. Additionally, the results from a proposed stoichiometric method [43] were employed to predict coal consumption. This method is a simple assumption to calculate the coal consumption; the product gas is assumed only typical components, i.e., hydrogen, carbon monoxide, carbon dioxide, and methane as shown eq. (1). The amount of coal consumption is calculated by the amount of oxygen injected and the carbon content of coal as shown eq. (2).

$\mathrm{CH}_{\mathrm{m}} \mathrm{O}_{\mathrm{n}}+\alpha \mathrm{O}_{2}+\beta \mathrm{H}_{2} \mathrm{O} \rightarrow \gamma \mathrm{H}_{2}+\delta \mathrm{CO}+\varepsilon \mathrm{CO}_{2}+\eta \mathrm{CH}_{4}$

$\mathrm{A}=(\mathrm{S} \cdot \mathrm{M} \cdot 1,200) /(22.4 \cdot \mathrm{C} \cdot \alpha)$

where $\mathrm{A}$ is coal consumption $(\mathrm{kg} / \mathrm{h}), \mathrm{S}$ is the amount of oxygen supply $\left(\mathrm{m}^{3} / \mathrm{h}\right), \mathrm{M}$ is mole fraction of $\mathrm{O}_{2}$ $(\mathrm{M}=1$ when pure oxygen is used as the gasification agent), $\mathrm{C}$ is the carbon content $(\%)$ taken by ultimate analysis.

As a comparison, the percentage error of the coal consumption bases the results obtained between the stoichiometric method and the balance computation are given in Table 6. It is observed that the maximum percentage error is less than $10 \%$ in the case of the linking-hole model, and for the coaxialhole model, it is just less than 7\%. Overall, the estimated results with the proposed stoichiometric method are useful for evaluating the coal consumption. This could be helpful for monitoring the cavity growth during the UCG process.

Table. 4. Balance computation of carbon (C).

\begin{tabular}{cccccccccc}
\hline & \multicolumn{3}{c}{ Coaxial model test 1} & \multicolumn{2}{c}{ Coaxial model test 2 } & \multicolumn{2}{c}{ Linking-hole model test 3 } \\
\cline { 2 - 10 } $\begin{array}{c}\text { Gas } \\
\text { composition }\end{array}$ & $\begin{array}{c}\text { Total amount } \\
\text { of product gas }\end{array}$ & $\begin{array}{c}\text { Balance of } \\
\text { C element }\end{array}$ & $\begin{array}{c}\text { Total amount } \\
\text { of product gas }\end{array}$ & $\begin{array}{c}\text { Balance of } \\
\text { C element }\end{array}$ & $\begin{array}{c}\text { Total amount } \\
\text { of product gas }\end{array}$ & $\begin{array}{c}\text { Balance of } \\
\text { C element }\end{array}$ \\
\cline { 2 - 11 } & $/[\mathrm{mol}]$ & $/[\mathrm{mol}]$ & $/[\mathrm{kg}]$ & $/[\mathrm{mol}]$ & $/[\mathrm{mol}]$ & $/[\mathrm{kg}]$ & $/[\mathrm{mol}]$ & $/[\mathrm{mol}]$ & $/[\mathrm{kg}]$ \\
\hline $\mathrm{CH}_{4}$ & 43.45 & 43.45 & 0.52 & 17.58 & 17.58 & 0.21 & 883.20 & 883.20 & 10.60 \\
$\mathrm{CO}$ & 887.44 & 887.44 & 10.65 & 1704.13 & 1704.13 & 20.45 & 3194.00 & 3194.00 & 38.33 \\
$\mathrm{CO}_{2}$ & 638.96 & 638.96 & 7.67 & 1403.09 & 1403.09 & 16.84 & 2880.96 & 2880.96 & 34.57 \\
$\mathrm{C}_{2} \mathrm{H}_{4}$ & 5.73 & 11.45 & 0.14 & 5.35 & 10.71 & 0.13 & 78.19 & 156.39 & 1.88 \\
$\mathrm{C}_{2} \mathrm{H}_{6}$ & 0.34 & 0.68 & 0.01 & 0.73 & 1.46 & 0.02 & 56.99 & 113.97 & 1.37 \\
$\mathrm{C}_{3} \mathrm{H}_{6}$ & 0.25 & 0.74 & 0.01 & 0.43 & 1.28 & 0.02 & 19.29 & 57.88 & 0.69 \\
$\mathrm{C}_{3} \mathrm{H}_{8}$ & 0.00 & 0.00 & 0.00 & 0.06 & 0.17 & 0.00 & 13.31 & 39.94 & 0.48 \\
\hline Total & 1576.17 & 1582.73 & 18.99 & 3131.37 & 3138.42 & 37.66 & 7125.95 & 7326.35 & 87.92 \\
\hline
\end{tabular}

Table. 5. Energy recovery rate.

\begin{tabular}{cccc}
\hline \multirow{2}{*}{ No. } & Amount C element & Gasified coal & Gasification rate \\
\cline { 2 - 4 } & $/[\mathrm{kg}]$ & $/[\mathrm{kg}]$ & $/[\%]$ \\
\hline Coaxial model test 1 & 18.99 & 24.23 & 49.12
\end{tabular}


Table. 6. Comparison of coal consumption bases on stoichiometric method and balance computation.

\begin{tabular}{cccc} 
No. & Test 1 & Test 2 & Test 3 \\
\hline $\begin{array}{c}\text { Coal consumption by } \\
\text { stoichiometric method /[kg] } \\
\text { Coal consumption by }\end{array}$ & 26.02 & 46.04 & 134.71 \\
$\begin{array}{c}\text { balance computation (Carbon) } /[\mathrm{kg}] \\
\text { Error percentage [\%] }\end{array}$ & 24.23 & 48.04 & 121.60 \\
\hline
\end{tabular}

\section{Conclusions}

In this study, the fracture and cavity growth inside a reactor in the simulated UCG-model experiments were evaluated using the results of $\mathrm{AE}$ and temperature profiles. The quantitative results of coal consumption were estimated using a proposed stoichiometric method. The following conclusions are drawn:

1) The experimental results indicate that there is a correlation between local temperature change and occurrence of AE activities in the gasifier. Generally, the magnitude of AE events increased gradually when the local temperature changed. Specifically, AE was active with sharp increases and decreases of temperature in the UCG reactor.

2) The located AE sources directly reflect the fracture distribution and the process of initiation and propagation of cracks, which provides reliable information for evaluating the failure and cavity growth of the gasification zone underground, and could form a database for visualizing the UCG process in a simulation.

3) The experiment conducted proved that more favorable thermodynamic conditions for increase oxygen supply rate were obtained using the oxygen-enriched air as gasification agent. The influence of linking-hole types in the system on the gasification effect is also considerable.

4) Estimated coal consumption based on the stoichiometric method using product gas compositions supports the results of the balance computation of carbon (the maximum error percentage was less than $10 \%$, which might be caused by not accounting for the water filtered by the purification system and the created tar content) throughout the gasification process. Estimation of coal consumption from product gas compositions could be helpful for monitoring the cavity growth during the UCG process.

5) The experiment conducted demonstrated that the oxygen-enriched air as react gas for sustaining the gasification process is a feasible option. In the present study, about 50\%-60\% oxygenenriched air was supplied to sustain the gasification. According to the experimental results, the average gas calorific value yielded in the linking-hole model was $12.41 \mathrm{MJ} / \mathrm{Nm}^{3}$, and values of 7.86 and $8.36 \mathrm{MJ} / \mathrm{Nm}^{3}$ were obtained in the two coaxial-hole models, which were improved by about $20 \%-30 \%$ compared with small-scale laboratory tests conducted using pure oxygen as the 
reactant gas in our previous work [43]. It was also realized that improvements in the gasification efficiency and cavity expansion in the coaxial UCG system must be achieved in future work.

\section{Acknowledgments}

This work was supported by the Japanese Society for UCG, Mikasa City, JSPS KAKENHI Grant Number JP15H02332, Research Fund for the Doctoral Program of Higher Education of HPU (RFDP) Fund Number 660207/018, Scientific and technological research projects of Henan Province (182102310020\&182102310889), Center of Environmental Science and Disaster Mitigation for Advanced Research of Muroran Institute of Technology and a Grant-in-Aid for Scientific Research (b), 21360441, from the Ministry of Education, Culture, Sports, Science and Technology (MEXT), Japan. The authors gratefully acknowledge their support. We earnestly appreciate the Editors' and Reviewers' work, and thanks a lot for their comments and suggestions.

\section{References}

[1] Luppens, J. A., Rohrbacher, T. J., Osmonson, L. M., Carter, M. D., 2009, Coal resource availability, recoverability, and economic evaluations in the United States-A summary. In Pierce, B. S., Dennen, K.O., editors. The National Coal Resource Assessment Overview: U.S. Geological Survey Professional Paper 1625-F, Chapter D, $17 \mathrm{p}$.

[2] Burton, E., Friedmann, J., Upadhye, R. Best practices in underground coal gasification; Lawrence Livermore National Laboratory: Livermore, CA, USA, 2006.

[3] BHP Billiton. Case Study B20: Electricity production using underground coal gasification (UCG). Newcastle, Australia, 2002.

[4] Friedmann, S. J. North America prospects for UCG in a carbon constrained, energy secure world. Presented at the Twenty-Fifth Annual International Pittsburgh Coal Conference, Pittsburgh, PA, Sep 29-Oct 2, 2008; Paper 26-1.

[5] Li, H., Yan, J., Yan, J., Anheden, M. Impurity impacts on the purification process in oxy-fuel combustion based CO2 capture and storage system. Appl Energy 2009;86:202-13.

[6] Hu, Y., Yan, J. Characterization of flue gas in oxy-coal combustion processes for CO2 capture. Appl Energy 2012;90:113-21.

[7] Alexander, Y. K. Early ideas in underground coal gasification and their evolution. Energies 2009;2:456-476.

[8] Creedy, D. P., Garner, K., Holloway, S., Jones, N., Ren, T. X. Review of underground coal gasification technological advancements; Report COAL R211; DTI/Pub URN 01/1041; Department of Trade and Industry Technology (DTI): London, 2001.

[9] Review of the feasibility of underground coal gasification in the UK; Cleaner Fossil Fuels Programme; DTI/Pub URN 04/1643; Department of Trade and Industry Technology (DTI): London, 2004.

[10] Sury, M., White, M., Kirton, J., Carr, P., Woodbridge, R., Mostade, M., Chappell, R., Hartwell, D., Hunt, D., Rendell N. Review of Environmental Issues of Underground Coal Gasification; Report COAL R272; DTI/ Pub URN 04/1880; Department of Trade and Industry Technology (DTI): London, 2004.

[11] Kreinin, E. V. Nontraditional thermal technologies for production of heavy-extractable fuels: Coal, hydrocarbons; OAO Gazprom: Moscow, Russia, 2004. 
[12] Lazarenko, S. N., Kreinin, E. V. Underground coal gasification in Kuzbass: New opportunities; Institute of Coal and Geochemistry, Siberian Branch of the Russian Academy of Sciences: Kemerovo, Russia, 2006.

[13] Gadelle, C., Lessi, J., Sarda, J. P. Underground coal gasification at Great Depth: The French field test of Bruay-En-Artois. Oil Gas Sci Technol Rev IFP 1982;37:157-81.

[14] Kurth, M., Depouhon, F., Patigny, J., Ledent, P. Linking and gasification in Thulin: A new endeavor. In Proceedings of the 12th Annual Underground Coal Gasification Symposium; DOE: Washington, DC, 1986;60-5.

[15] Chandelle, V. The pushing through project of the gasification channel in Tulin Coal Field. Collect Translat Works Min Technol 1992;13(2):5-7.

[16] Green, M. B. Underground coal gasifications: A joint European trial in Spain; Report Coal R196; DTI Pub URN99/1093; Department of Trade and Industry Technology (DTI): London, 1999.

[17] Hill, R. W. Review of the CRIP process. In Proceedings of the 12th Annual Underground Coal Gasification Symposium; DOE: Washington, DC, 1986 (Report DOE/FE/60922-H1).

[18] Gregg, D. W., Edgar, T. F. Underground coal gasification. AIChE J. 1978;24:753-81.

[19] Viability of underground coal gasification in the "Deep Coals" of the Powder River Basin, Wyoming; Prepared for the Wyoming Business Council Business and Industry Division State Energy Office; GasTech, Inc.: Casper, WY, 2007. Combust Explos Shock Waves 1993;29:148-54.

[20] Kostúr K, Laciak M, Durdan M, Kacur J, Flegner P. Low-calorific gasification of underground coal with a higher humidity. Measurement 2015;63:69-80.

[21] Pei, P., Nasah, J., Solc, J., Korom, S. F., Laudal, D., Barse, K. Investigation of the feasibility of underground coal gasification in North Dakota, United States. Energy Convers Manage 2016;113:95-103.

[22] Wang, Z., Huang, W., Zhang, P., Xin, L. A contrast study on different gasifying agents of underground coal gasification at Huating Coal Mine. International Journal of Coal Science and Engineering 2011;17(2):18186.

[23] Stanczyk, K., Howaniec, N., Smolinski, A., Swiadrowski, J., Kapusta, K., Wiatowski, M., et al. Gasification of lignite and hard coal with air and oxygen enriched air in a pilot scale ex situ reactor for underground gasification. Fuel 2011;90:1953-62.

[24] Laciak M, Kostúr K, Durdan M, Kacur J, Flegner P. The analysis of the underground coal gasification in experimental equipment. Energy 2016;114:322-43.

[25] Shu-gin, L., Yuan-yuaon, W., Ke, Z., Ning, Y. Enhanced-hydrogen gas production through underground gasification of lignite. Min Sci Tech 2009;19:384-94.

[26] Perkins, G., Sahajwalla, V. A Numerical Study of the Effects of Operating Conditions and Coal Properties on Cavity Growth in Underground Coal Gasification. Energy Fuels 2006;20(2):596-608.

[27] Olateju, B., Kumar, A. Techno-economic assessment of hydrogen production from underground coal gasification (UCG) in Western Canada with carbon capture and sequestration (CCS) for upgrading bitumen from oil sands. Appl Energy 2013;111:428-40.

[28] Eftekhari, A.A., Wolf, K.H., Rogut, J., Bruining, H. Energy and exergy analysis of alternating injection of oxygen and steam in the low emission underground gasification of deep thin coal. Appl Energy 2017;208:62-71.

[29] J. Kacur, M. Durdan, M. Laciak, P. Flegner, Impact analysis of the oxidant in the process of underground coal gasification, Measurement 51 (2014) 147-155.

[30] M.M. Khan, J.P. Mmbaga, A.S. Shirazi, J. Trivedi, Q. Liu, and R. Gupta. "Modelling Underground Coal Gasification - A Review”, Energies, 2015;8:12603-68. 
[31] H. Nourozieh, M. Kariznovi, Z. Chen, and J. Abedi. "Simulation Study of Underground Coal Gasification in Alberta Reservoirs:Geological Structure and Process Modeling”, Energy Fuels, 2010;24:3540-50.

[32] Cui, Y., Liang, J., Wang, Z., Zhang, X., Fan, C., Liang, D., Wang, X. Forward and reverse combustion gasification of coal with production of high-quality syngas in a simulated pilot system for in situ gasification. Appl Energy 2014;131:9-19.

[33] Daggupati S, Mandapati RN, Mahajani SM, Ganesh A, Sapru RK, Sharma RK, et al. Laboratory studies on cavity growth and product gas composition in the context of underground coal gasification. Energy 2011;36:1776-84.

[34] Daggupati S, Mandapati RN, Mahajani SM, Ganesh A, Mathur DK, Sharma RK, et al. Laboratory studies on combustion cavity growth in lignite coal blocks in the context of underground coal gasification. Energy 2010;35(6):2374.

[35] Cena RJ, Thorsness CB. Underground coal gasification data base. Report No.UCID-19169. U.S. DOE. Livermore, CA: Lawrence Livermore National Laboratory; 1981.

[36] Perkins G, Sahajwalla V. A numerical study of the effects of operating conditions and coal properties on cavity growth in underground coal gasification. Energy Fuels 2006;20:596.

[37] Shannon MJ, Thorsness CB, Hill RW. Early cavity growth during forward burn. Report no. UCRL-84584. U.S. DOE, Livermore, CA: Lawrence Livermore National Laboratory; 1980.

[38] Thorsness CB, Hill RW. Coal block gasification: laboratory results and field plans. Report no. UCRL85906. U.S. DOE, Livermore, CA: Lawrence Livermore National Laboratory; 1981.

[39] Wellborn TA. Linear burning rates of Texas lignite's. Masters thesis. Austin, TX: The University of Texas at Austin; 1981.

[40] Poon SSK. The combustion rates of Texas lignite cores. Masters thesis. Austin, TX: The University of Texas at Austin; 1985.

[41] Reginald, H., Jr. Acoustic emission/microseismic activity; Taylor \& Francis: Leiden, The Netherlands, 2003.

[42] Su, F., Itakura, K., Deguchi, G., Ohga, K. Monitoring of coal fracturing in underground coal gasification by acoustic emission techniques. Appl Energy 2017;189:142-56.

[43] Su, F., Itakura, K., Deguchi, G., Ohga, K., Kaiho, M. Evaluation of energy recovery from laboratory experiments and small-scale field tests of underground coal gasification (UCG). Journal of MMIJ 2015;131:203-18.

[44] Wiatowski, M., Kapusta, K., S' wia drowski, J., Cybulski, K., Ludwik-Pardała, M., Grabowski, J., Stan' czyk. K. Technological aspects of underground coal gasification in experimental "Barbara" Mine. Fuel 2015;159:454-62.

[45] Su, F., Matsubara, S., Yoshida, R., Itakura, K. Evaluation of Energy Recovery during Underground Coal Gasification (UCG) Experiment using Artificial Coal Seam. J.MMIJ, 2015;B-6:36-39, (Hakodate, Japan), 2015.6, 